\title{
A Valuation Framework for Informing Grid Modernization Decisions: Summary
}

\section{A summary of the principles and process for valuing grid services and technologies}

\section{March 2019}

Grid Modernization Laboratory Consortium

National Association of Regulatory Utility Commissioners 


\section{DOCUMENT AVAILABILITY}

Reports produced after January 1, 1996, are generally available free via US Department of Energy (DOE) SciTech Connect.

Website www.osti.gov

Reports produced before January 1, 1996, may be purchased by members of the public from the following source:

National Technical Information Service

5285 Port Royal Road

Springfield, VA 22161

Telephone 703-605-6000 (1-800-553-6847)

TDD 703-487-4639

Fax 703-605-6900

E-mail info@ntis.gov

Website http://classic.ntis.gov/

Reports are available to DOE employees, DOE contractors, Energy Technology Data Exchange representatives, and International Nuclear Information System representatives from the following source:

Office of Scientific and Technical Information

PO Box 62

Oak Ridge, TN 37831

Telephone 865-576-8401

Fax 865-576-5728

E-mail reports@osti.gov

Website http://www.osti.gov/contact.html

This report was prepared as an account of work sponsored by an agency of the United States Government. Neither the United States Government nor any agency thereof, nor any of their employees, makes any warranty, express or implied, or assumes any legal liability or responsibility for the accuracy, completeness, or usefulness of any information, apparatus, product, or process disclosed, or represents that its use would not infringe privately owned rights. Reference herein to any specific commercial product, process, or service by trade name, trademark, manufacturer, or otherwise, does not necessarily constitute or imply its endorsement, recommendation, or favoring by the United States Government or any agency thereof. The views and opinions of authors expressed herein do not necessarily state or reflect those of the United States Government or any agency thereof. 


\section{A Valuation Framework for Informing Grid Modernization Decisions: Summary}

A summary of the principles and process for valuing grid services and technologies

Grid Modernization Laboratory Consortium Members:

L. C. Markel ${ }^{8}$

A. Cooke ${ }^{2}$

S. W. Hadley ${ }^{1,8}$

A. D. Mills ${ }^{5}$

P. W. O'Connor ${ }^{1}$

V. N. Vargas ${ }^{6}$

A. K. Wolfe ${ }^{1}$

V. Koritarov ${ }^{3}$

C. A. Goldman ${ }^{5}$

M. Kintner-Meyer ${ }^{2}$

P. Gagnon ${ }^{4}$

M. Ruth ${ }^{4}$

A. Somani ${ }^{2}$

G. Porro ${ }^{4}$

R. F. Jeffers 6

In partnership with the National Association of Regulatory Utility Commissioners
J. Brinch ${ }^{7}$
D. Byrnett ${ }^{7}$
K. Worthington ${ }^{7-}$

${ }^{1}$ Oak Ridge National Laboratory

${ }^{2}$ Pacific Northwest National Laboratory

${ }^{3}$ Argonne National Laboratory

${ }^{4}$ National Renewable Energy Laboratory

${ }^{5}$ Lawrence Berkeley National Laboratory

${ }^{6}$ Sandia National Laboratories

${ }^{7}$ National Association of Regulatory Utility Commissioners

${ }^{8}$ SRA International Inc., a General Dynamics Information Technology company

March 2019 



\section{Acknowledgments}

The Lab Team and Stakeholder Advisory Group would like to express a deep appreciation to the late Jeannette "Jan" Brinch of the National Association of Regulatory Utility Commissioners (NARUC) for her experience, tenacity, and collaborative spirit throughout the 3 years of this project. Jan's contributions were essential to the project's accomplishments.

The Lab Team wants to thank our Stakeholder Advisory Group members who provided guidance and support through attendance at webinars and multi-day seminars; helpful comments on draft papers; encouragement on the framework; and insights into what those involved in the development, operation, and regulation of the grid system outside of the national laboratory system know about the issues and concerns regarding grid modernization valuation. Their expertise and wealth of knowledge were instrumental in shaping and directing the project. Kerry Worthington, Danielle Sass Byrnett and Dominic Liberatore of the National Association of Regulatory Utility Commissioners provided coordination between the Stakeholder Advisory Group and the Lab Team.

\section{Grid Valuation Framework Stakeholder Advisory Group (past and present)}

Michael Bailey, Senior Engineer on System Adequacy, Western Electricity Coordinating Council Denis Bergeron, Director of Energy Program, Maine Public Utilities Commission Betsy Beck, Director, Transmission Policy, American Wind Energy Association Gary Brinkworth, Director of Technology Innovation, Tennessee Valley Authority (TVA)

Lilian Bruce, Strategic Research, Electric Power Board, Chattanooga

John Buechler, Director, Eastern Interconnection Planning Council

Erin Erben, Rates and Financial Planning Manager, Tacoma Power, and EPRI (former)

Ed Finley, Chairman - North Carolina Utilities Commission; Alternate: Kim Jones

Ben Hobbs, Director, Environment, Energy, Sustainability \& Health Institute, Johns Hopkins University

David Kolata, Executive Director, Citizens Utility Board

Ron Lehr, Consultant - Western Clean Energy Advocates, Western Grid Group

Jonathan Lesser, Continental Economics Inc.

Enrique Mejorada, Director of Energy Policy Modeling and Analysis, Pacific Gas \& Electric

Rohan Ma, Solar City Corporation (former); Alternate: Ryan Hanley (former)

Eliah Gilfenbaum, Tesla

Michal Moore, Earth-Energy Systems Integrated Graduate Education and Research Training (IGERT), Cornell University

Jeff Morris, Representative, Washington State Legislature

Bernard Neenan, EPRI (retired), Energy Resource Economics (current)

Ray Palmer, Federal Energy Regulatory Commission (FERC) (former)

Jeffery Roark, Power Delivery \& Utilization, Electric Power Research Institute (EPRI)

Matthew Shuerger, Commissioner, Minnesota PUC

Sekou Sidime, Commonwealth Edison

Tom Sloan, Kansas State House of Representatives (former)

J. T. Smith, Director, Policy Studies, Midcontinent ISO

Nick Wagner, Commissioner, Iowa PUC

David Whiteley, Director, Eastern Interconnection Planning Council (former)

This research was supported by the Grid Modernization Initiative of the US Department of Energy (DOE) as part of its Grid Modernization Laboratory Consortium, a strategic partnership between DOE and the national laboratories to bring together leading experts, technologies, and resources to collaborate on the goal of modernizing the nation's grid. We would like to thank all of our DOE sponsors, and especially Christopher Irwin, who has been our champion and guiding light on what a grid valuation framework can be and can accomplish. 



\section{Acronyms and Abbreviations}

ALR

ASHRAE

DER

DOE

EIPC

FERC

GAAP

GMLC

IRP

ISO

LOLP

MWh

NERC

PUC

RI

SAG

TPL

TVA

adequate level of reliability

American Society of Heating, Refrigerating and Air-Conditioning Engineers distributed energy resources

US Department of Energy

Eastern Interconnection Planning Collaborative

Federal Energy Regulatory Commission

generally accepted accounting principles

Grid Modernization Laboratory Consortium

Integrated Resource Plan

International Organization for Standardization

loss of load probability

Megawatt-hour

North American Electric Reliability Corporation

public utility commission

Rhode Island

Stakeholder Advisory Group

transmission planning

Tennessee Valley Authority 



\section{Contents}

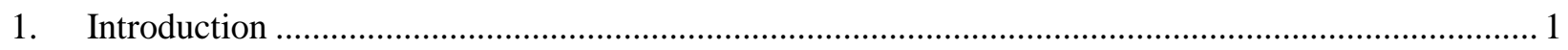

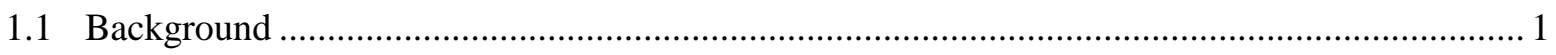

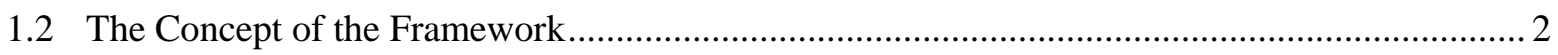

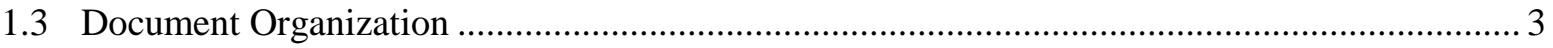

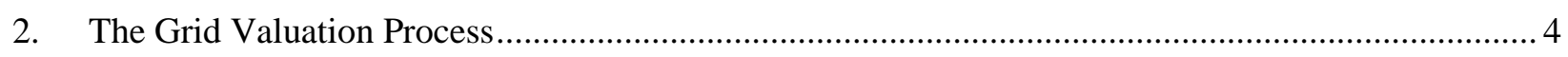

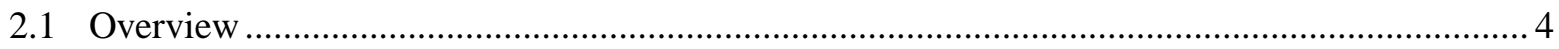

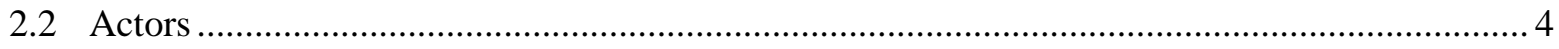

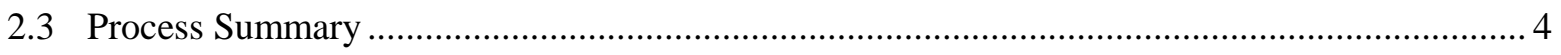

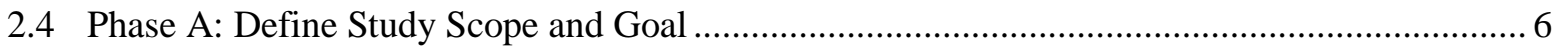

2.5 Phase B: Frame Valuation Criteria.................................................................................. 11

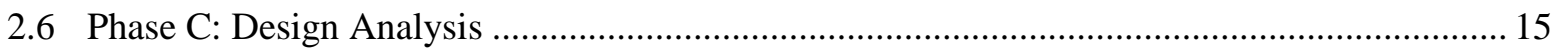

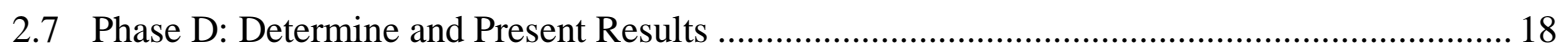

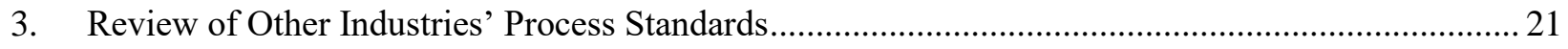

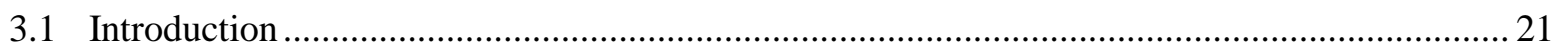

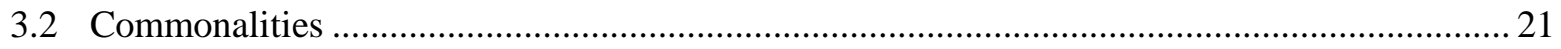

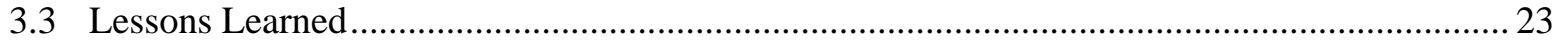

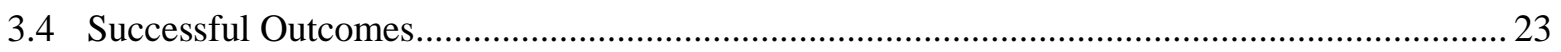

3.5 Considerations for Increasing Consistency of Grid Valuation Processes ................................ 24

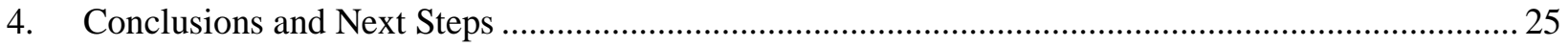

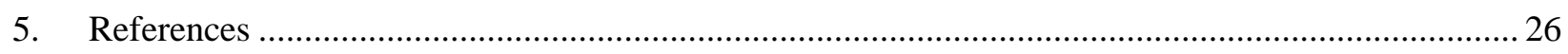





\section{Introduction}

\subsection{Background}

Across the electric power industry, a diverse stakeholder community applies a variety of methodologies to assess the value of courses of actions, ranging from investments in generation, transmission or distribution assets; to compensation mechanisms for distributed technologies; to a multitude of other policies related to projects in the electricity sector. The resulting value assessments often vary widely for the same or similar types of projects. As an example, two studies addressing the value of rooftop solar photovoltaic (PV) installations came to significantly different conclusions ${ }^{1}$; the studies chose different valuation metrics and analysis methods. This example is not unusual: often valuation studies are not comparable or repeatable because of differences in assumptions with respect to economic and engineering inputs; time, geographic, and power system scales; the closed-source inner workings of modeling tools and analysis methodologies employed for the valuation; stakeholder-specific choices of the key metrics or grid attributes that are the focus of the valuation; and/or choices of which grid investment, design or operation alternatives to compare. Investment decisions and policy options are reviewed and interpreted by multiple stakeholders, who have different motivations, interests, and obligations.

The values of a grid design option can no longer be expressed by just using historical cost-emissionsreliability metrics. Nor can major decisions be made through closed analysis without consideration of the different stakeholders affected by a decision. This valuation framework provides a structure for valuation that is deliberate, inclusive, and transparent, documenting the intermediate and final results to ensure clarity, accountability and repeatability.

This document summarizes the guidelines for the framework for valuing grid generation, transmission, and distribution assets - including distributed generation and storage — and the services they provide, as well as policy options commonly evaluated in the context of the electric power grid. The framework is the primary product of the US Department of Energy's (DOE) Grid Modernization project titled "Grid Services and Technologies Valuation Framework Development," also known by its project number, GMLC 1.2.4. A team of national laboratory personnel have organized its development through a review of existing valuations and standards, experience with valuation exercises, and discussions with a Stakeholder Advisory Group (SAG) comprised of industry, regulators, and other organizations. The detailed guidelines are available in a separate Valuation Framework Guidelines (Markel et al. 2019).

The field of accounting has a systematic set of generally accepted accounting principles (GAAP). Broad adoption of GAAP by professionals promotes consistency among analysts that facilitates apples-to-apples comparisons and ensures accurate, objective, verifiable and repeatable reporting of financial status. Similarly, the GMLC 1.2.4 project team envisions a long-term aspirational goal of establishing a set of generally accepted valuation principles for application to grid decisions that may in the future be adopted by stakeholders in the electricity sector.

The Valuation Framework Guidelines represents a first step toward that aspirational goal. It seeks to address inconsistencies, lack of transparency, and intrinsic biases often inherent in grid-related valuation studies. There are a great diversity of technologies, options, decision makers and other stakeholders involved in valuation studies; it is not realistic to expect that one standard method could be developed to evaluate grid options applicable to such a wide range of issues and technologies. Instead of a prescriptive

\footnotetext{
${ }^{1}$ E.g., Trabish, Herman K., "How two value-of-solar studies add up to no clear value of solar: Is rooftop solar really worth 90\% less in Montana than in Maryland?" Utilitydive.com, May 10, 2018, https://www.utilitydive.com/news/how-two-value-of-solar-studies-add-up-to-no-clear-value-of-solar/522892/
} 
methodology, the Valuation Framework Guidelines proposes a set of elements, processes, and internalconsistency checks that could improve the ability to value grid services, technologies, and policies comprehensively, objectively and transparently.

The framework embodies a systematic approach to the definition and documentation of the scale, scope, and assumptions that influence any grid-related valuation or modeling activity. It is intended to improve the ability of electricity-sector decision makers, analysts, and stakeholders to conduct, understand the basis of, and interpret the results of valuation studies, with high levels of transparency, repeatability, and extensibility. Such outcomes should also enable more effective comparisons of results among similarly constructed studies in a way that enables improved leveraging of prior work.

\subsection{The Concept of the Framework}

"Valuation" in this context is the process of determining the relative worth, utility, or importance (i.e., value) of options or alternatives to allow their comparison in ways that are clear, transparent, and repeatable. "Value" does not refer only to monetary savings and costs. Value may encompass multiple elements and associated physical measures such as reliability, resiliency, flexibility, sustainability, security, environmental quality, public health and safety, and economic impact.

Metrics are a means to express attributes and performance measures that constitute this broad definition of value. Metrics may be quantitative or qualitative. Identifying quantitative metrics for some of the elements is straightforward. However, in many cases, defining metrics (especially qualitative metrics) may be far less clear and may be controversial. Externalities (effects or consequences that are not explicitly included in the costs attributed to a grid option under evaluation) can also be very difficult to define and quantify but may be extremely important factors in grid-related decision making. Because it can be difficult and controversial to define many quantitative or qualitative metrics, it is important to be explicit about how all metrics are defined, are gauged, and contribute to the valuation.

The GMLC team has drawn on the use of software development frameworks to apply the concept of a "framework" for valuation in the electricity sector. Software development frameworks identify what formal components are necessary in developing software to ensure an efficient process so that the resulting software meets the functional requirements. Similarly, the Valuation Framework Guidelines defines essential elements or activities for valuing grid alternatives to support decision making so that the valuation results support the information upon which the decision makers actually will base their choice. The long-term vision for this project is to construct a unified framework that accomplishes the following three interrelated goals:

- Goal 1: Develop a Grid Services and Technology Taxonomy and an associated glossary that documents and classifies services and technologies, the different types of products that these services and technologies bring to the power system, and metrics relevant and applicable to each.

- Goal 2: Describe Valuation formally, as an explicit Process, documenting the linkages among the methods, metrics, and perspectives outlined in the taxonomy.

- Goal 3: Develop BroadlyApplicable, Stakeholder-Vetted Guidelines for the design, implementation, and documentation of a formalized valuation process.

The Valuation Framework Guidelines begins to address these three goals, with a focus on Goal 2, to assemble a framework for valuation of electricity sector alternatives.

\section{Attributes of the Framework}

The framework presented herein is intended to promote an informed and transparent analysis for gridrelated decision making. Just as important, the valuation process aims to assist when there is a rethinking 
or revisiting of previous decisions, perhaps in the face of practical resource constraints or iterative feedback from stakeholders. The framework is meant to be flexible and adaptable to focus on the problem at hand without being burdensome.

There will be considerable variation in how the valuation process is implemented. Analysts may use any of a number of modeling approaches or analytical tools. Similarly, factors such as uncertainty, data availability, and data quality will influence the accuracy of valuation analyses. These same factors could impose restrictions on the level of modeling detail or analysis that analysts or the organizations sponsoring the valuation analyses deem it worthwhile to conduct.

\section{Who is the Audience?}

The primary audience for this framework is those who specify, oversee, and use valuation studies (i.e., decision makers), helping them to make sure those who perform/implement the analyses are aligned with the decision makers' needs. As a consequence, the analysis community will find it useful and important to understand the framework process. Section 3 of the full guidance report (Markel et al. 2019) provides greater detail on the process steps and would be useful for this audience. The broader audience includes a varied community of stakeholders: utilities, power generators and developers, wholesale market operators, regulators, local governments, and investors. Additional stakeholders have an interest in and will be affected by valuation studies conducted in accordance with the framework: electricity end-users and facility owners/operators, public interest groups, chambers of commerce and business associations, organizations concerned with public health and safety, etc.

The concerned stakeholders include groups that reflect varied roles, responsibilities, constraints, and interests. For example, a utility or generation company considering an investment ultimately must decide for itself to commit to an expenditure. Likewise, a public utility commission (PUC) may in fact be a decision maker that is constrained in the type, nature, and timing of its engagement in a utility-directed valuation study because of regulatory procedural requirements. Other organizations may use the framework to better understand the value of grid-related technologies or services and inform the public or decision makers.

It is important to acknowledge that institutional dynamics and vested interests influence the entire process, especially approaches to stakeholder engagement. The form of stakeholder engagement depends upon multiple factors, including the type of valuation and who is conducting the valuation (e.g., a commission-convened valuation, a valuation that a utility is doing on its own behalf to support a decision or proposal, or other entities interested in understanding and informing others on grid-related issues). Some stakeholders may have an overriding issue or objective and may not be swayed by any analysis or valuation comparison. While such stakeholder priorities should be considered to some extent during the valuation process, doing so in a constructive manner can be challenging.

\subsection{Document Organization}

The organization of the remainder of this summary document is as follows:

- Section 2 provides an overview of the 4 phases and 11 steps of the framework.

- Section 3 draws upon other disciplines' development of process-specific standards and guidelines to discuss the lessons learned to transition the framework guidelines toward a possible industry standard.

- Section 4 discusses conclusions and possible next steps for the GLMC 1.2.4 effort.

- Section 5 presents the references used in the paper. 


\section{The Grid Valuation Process}

\subsection{Overview}

Our goal of formally delineating valuation as a process is particularly challenging for three reasons. First, the process needs to be applicable to an enormous array of potential electrical grid-related decisions. Second, the process needs to be amenable to a wide assortment of users and implementers - the organizations that initiate a valuation, their stakeholders, and analysts, all with divergent resources, knowledge, experience, and so on - in situations where resources available for the valuation study may range from highly constrained to seemingly unlimited. Third, the process itself is complex, with many elements that unfold and interact over time in a manner that is only loosely sequential, with activities that are often simultaneous, interactive, and/or iterative.

In a valuation assessment, outcomes of two or more alternatives are compared on the basis of differences in their characteristics or metrics. The difference between the metrics of two or more alternatives is considered to be an impact, and impacts are then transformed into values based on the perspectives of decision makers. These perspectives have two primary components: (1) whether a given impact is a positive or a negative relative change, or neither, and (2) what decision-making criteria guide the ultimate way a value is reported and interpreted. The impacts of each alternative are presented in a way that informs the decision for which the valuation effort was conducted.

When evaluating two or more alternatives, decision makers are often presented with arguments and information about alternatives that were derived from disparate methods and, as a result, may defy comparison. Decision makers also often need to address conflicting priorities among multiple stakeholders. The framework provides a guide for marshaling stakeholders, metrics, and evidence through the decision-making process in a systematic and transparent manner. Walking through a systematic process of scoping and conducting a valuation will create a consistent vision of how a valuation study should be executed. This same valuation process can also be used to interpret and assess valuation studies over which a reviewer has no direct control. By working through the same steps and applying the same systematic perspective and standards, users will add to the credibility and comparability of any study.

\subsection{Actors}

The framework process outlined in this section involves three sets of actors. The decision maker is the instigator of the study and recipient of the results or recommendations from the study, who will make the ultimate decision. The decision maker may be a single person (e.g., senior executive at a utility, energy services company, or public interest group) or a body of people (e.g., board of directors, regulatory board, legislative body). The second set of actors is the analysis team (analysts, modelers, consultants) that will conduct most of the detailed analysis. The team may be comprised of internal staff from the decisionmakers' organization, hired consultants or subcontractors, representatives from other interested organizations, or combinations of these. Third, stakeholders are those who are affected by the ultimate decision and want to have input in the valuation study. Each actor will have different roles and levels of involvement for the various steps in the framework process.

\subsection{Process Summary}

The valuation process starts when a decision maker decides to do a valuation study using the framework and ends with results and recommendations based on the information developed. In this section, we 
outline the 4 phases with 11 steps in this framework, we provide more detail on each step in the following sections. ${ }^{2}$

To present this complex valuation process in a tractable way, we organize it into two broad tiers: phases and steps. Phases are roughly sequential stages of the valuation process that depict major aspects of the valuation process. Steps outline the activities that are necessary to accomplish that phase of the study in practice. We suggest four main phases, once a decision has been made to conduct a valuation study:

A. Define the scope and goal-including articulation of purpose, alternatives, and description of stakeholder engagement;

B. Frame the valuation criteria - through identification of key metrics and means to address valuation based upon multiple criteria;

C. Design the analysis_-including methodology selection, input data, and treatment of uncertainty; and

D. Determine and document results_-including assessment, integration, and presentation in understandable form.

The 11 steps that span the 4 phases of the valuation framework process are identified in Figure 1.

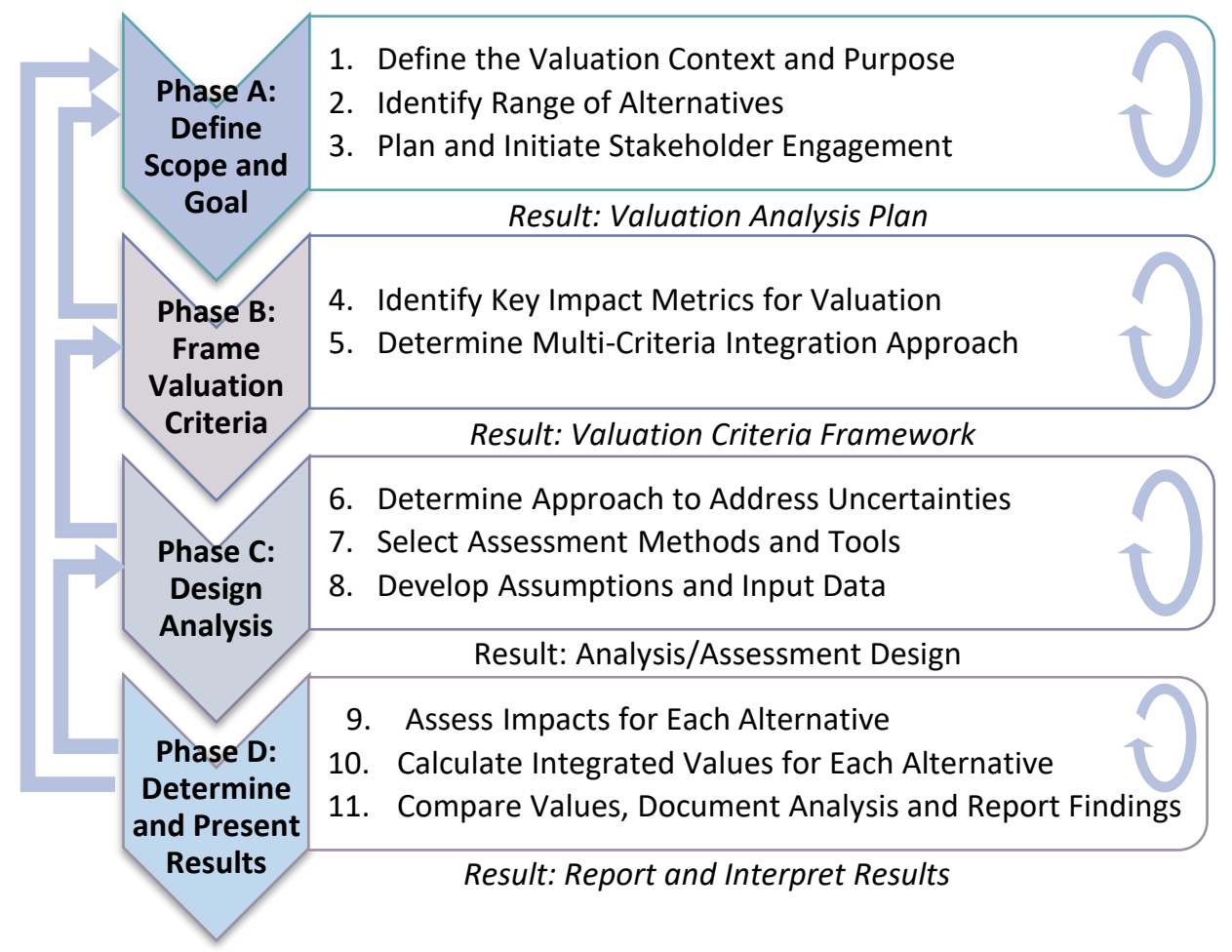

Figure 1. Valuation framework process

Conceptually, in phase A, the first three steps of the valuation framework can be considered the scoping phase of the study - carefully defining the purpose, context, relevant stakeholders, and alternatives to be considered.

\footnotetext{
${ }^{2}$ These steps and the following discussion are based loosely on Boardman et. al. (2006) and then refined and adopted for the purpose of the valuation framework by the GMLC team.
} 
In the next phase (B), defining the basis for the valuation, there are two steps to frame the information required to characterize alternatives (i.e., the impacts and metrics). In step 4, the users define the decision criteria for the study and then, in step 5, determine an approach to integrate or consolidate the metrics to portray the value of each alternative. (Note that "value" is often a complex concept and may not be reducible to a single number or a quantitative trade-off relationship among metrics.)

The third phase (C), designing the analysis, consists of three steps for constructing the study, including the tools, assumptions and input data (steps 7 and 8) to be used. This phase includes deliberately deciding how to consider uncertainty in the analysis (step 6) and consolidate predicted impacts from the different alternatives.

The final phase (D) is to calculate, analyze, interpret and present the results. The three steps in this phase are the calculation of key metrics; interpretation and presentation of the resulting values (steps 10 and 11); and reporting of the comparison among alternatives to guide decision making (step 9).

Many of the steps — such as characterizing stakeholder engagement - have multiple aspects, and their output will inform numerous other steps and several, possibly even all, of the four major phases. While the phases are generally sequential, the steps may not be. The analysis team may focus on activities in multiple steps simultaneously (or sub-groups of the analysis team may focus on different steps), and then the results or conclusions of some steps will further define the inputs of others. The results of one step may change the inputs or assumptions of a step listed previously (i.e., an iterative process). This iteration is shown by the arrows on the left and the circular arrows within the descriptors in Figure 1. The iteration is especially true for the first phase, where the study's objectives, scope, decision criteria, and rules of engagement are specified. To drive the valuation methodology process to a conclusion, metrics are a common currency for matching a question (Step 1) with appropriate tools and methods (Step 7) and providing the results presented (Step 11).

Assessments are complex and multi-variate. Determining the proper evaluation methodology (including the basis for evaluation as well as the selection of types of models) is as much an art as a science. The valuation process is far from being automated or even deterministic. The valuation framework can best be used by knowledgeable users. Thus, it is not designed to select models (or lists of eligible models) but rather to suggest the tools (including models) and analysis procedures to be employed.

The framework assumes that analysts are already knowledgeable regarding the grid system under study and details of the methods, tools, and models available. The user may well apply the valuation framework iteratively, choosing not only among models and tools but also among methodologies to calculate metrics and impacts, each of which may employ different sets of tools.

Documenting the decision process used to define the evaluation methodology and the reasons for choices made is key to transparency and promotes an alignment of objectives and methods that ensures valid and unbiased technical analyses.

\subsection{Phase A: Define Study Scope and Goal}

The first phase involves defining the overall scope of a study and developing a plan for accomplishing the study (project work statement, resources needed, schedule, key milestones, and so forth.) After the initial decision that a study should be conducted, the framework begins with activities that include defining the study purpose and the external factors that are driving or influencing the rationale for the study; broadly defining the different options or alternatives to be studied; and identifying stakeholders, contacting them for the initial engagement, and planning for continued engagement. These three steps are tightly 
interrelated. Thus, in defining the scope, one also begins to identify the key stakeholders and possible alternatives to be considered.

Thus, the activities operate iteratively and somewhat in parallel, rather than sequentially. For example, an initial desire by a decision maker or decision-making body to conduct a study may kick off the entire process (Step 1), but relevant stakeholders may need to be consulted (Step 3) before the alternatives to be compared can be finalized (Step 2). ${ }^{3}$ In two illustrative studies cited below, decision makers consulted stakeholders at the beginning of the process to help define the scope and select alternatives:

- $\quad$ The Tennessee Valley Authority (TVA) first assembled a diverse stakeholder group (Step 3) to help scope the bounds of TVA's valuation and marginal rate-setting for distributed technologies (Step 1) (TVA 2015a). This set of stakeholders included representatives from rural and urban load-serving entities across the region, consumer groups, environmental groups, solar installers, and technical experts.

- In 2009, DOE sponsored in-depth transmission planning efforts for the three US electrical interconnections. The Eastern Interconnection Planning Collaborative (EIPC), a group of the eastern region's main transmission planning authorities, first created a Stakeholder Steering Committee [Step 3] to propose the alternatives to be considered [Step 2] (EIPC 2011).

\section{Step 1: Define the Valuation Context and Purpose}

\section{Objectives}

To define the purpose and scope of the valuation study and to develop an initial study plan.

\section{Approach}

Conceptually, the valuation process is initiated in response to a problem, condition, or issue that presents a choice regarding how best to proceed. Step 1 includes specifying the scope by defining the context and objective of the study in terms of the analysis question(s) to be answered. This step defines the purpose of the valuation; identifies the aspects of the power system to be examined; poses, in general terms, the issues that the valuation seeks to address; and sets the physical boundaries and the temporal range for the analysis. Documenting the issue or question and what one hopes the discussion/choice of alternative will accomplish - i.e., what constitutes a good outcome - helps ensure that stakeholders, decision makers, and analysts have consistent viewpoints about issues and alternatives.

While it may seem obvious, it is essential to document the circumstances, issues, and objectives that motivate initiating a valuation study. The discipline of succinctly setting down the issue to be addressed and what the decision maker hopes to accomplish (e.g., serve a growing demand for electricity at minimal cost while meeting reliability criteria) provides the basis for choosing which parts of the power system to examine, alternatives to be considered, stakeholders to contact, and performance metrics on which to base a decision. These choices will in turn inform the choice of methods and tools for dealing with uncertainty/unknowns, performing the analysis, and characterizing the results of the analysis.

Valuation addresses situations where there are multiple performance metrics (e.g., electricity price, land use, job creation, resilience) and the trade-offs among those metrics are not straightforward. Being explicit in what one views as a good outcome differentiates a valuation study (i.e., what is the value of choosing this alternative?) from a least-cost planning study (i.e., what is the lowest lifecycle cost?), although low cost will likely be one of the metrics used. The many alternatives available for expanding or

\footnotetext{
${ }^{3}$ An analogy is that when putting on a spare tire, you don't tighten one lug nut fully, then do the next, then the next, until all five are done. Rather, you tighten one nut lightly, then follow with light tightening of nuts 2, 3, 4 and 5 . Only after all five are in place and lightly tightened do you fully tighten each nut in turn. Similarly, exercising the steps in the valuation methodology is a round-robin process as much as a sequential one.
} 
upgrading the modern grid make it difficult to clearly and quantitatively define an objective that is likely to easily achieve consensus acceptance among stakeholders and decision makers.

One way to approach this step is to begin to document the scope of the study by formulating the problem and the system elements that it affects. This specification of study requirements (which will evolve and become more specific or detailed in subsequent steps) may include the following types of information:

- Primary purpose: i.e., aspect(s) of the power system one is trying to improve or optimize

- Area of interest (geographic).

- System(s), sectors (e.g., generation, transmission, distribution, end use), equipment or procedure(s) of interest (e.g., tariffs, generators: what is being modeled or evaluated - e.g., a feeder, a bulk power system, generators and loads).

- Time frame (start and end of time period of interest for implementing the alternative and evaluating its expected performance).

- Impacts: A preliminary list of relevant impacts and their metrics can be identified. However, key stakeholders (stakeholder engagement, Step 3) will further inform this list/selection and a more definitive list of metrics is developed in Step 4.

The analysis is constrained by the time and resources available to conduct the study. The study scope, number of metrics considered, and level of detail of the analysis must be consistent with the time and budget available. A detailed plan for the study must be developed, including schedule, tasks and milestones, expenditures, study participants and their roles and responsibilities, and list of stakeholders to be involved.

\section{Results/Documentation}

- A succinct statement of the purpose of the valuation, with context, including

- Whose perspective is primary (e.g., lead decision maker)

$\circ$ The purpose of the decision (e.g., policy development, investment)

$\circ$ The time frame over which impacts are considered in the valuation

- The geographic area for consideration

- A high-level specification of the overall process to be followed

- A preliminary list of stakeholders to be involved in the study

- An initial draft of the study plan, including time frame, budget, milestones, and evaluation team

- Identification of related studies that can inform selection of metrics and methods

- Sources of data to inform the analysis

\section{Interaction with other steps}

Steps 1,2, and 3 in the first phase are all closely interrelated. For subsequent phases, the characterization of the question and scope of analysis will inform the choice of metrics (Step 4), the relative weighting of metrics to influence the ultimate valuation-based decision (Step 5), and the nature and rigor of the models, tools, and analysis methods to be used (Step 7). The study plan developed during the first phase will govern all subsequent phases and their individual steps. 


\section{Step 2: Identify the Alternatives}

\section{Objectives}

To select which alternatives to analyze and compare.

\section{Approach}

In this step, the goal is to clearly identify the specific alternative courses of action that could be implemented. The scope of alternatives varies significantly based on the context of the decision. These can range from narrow specification of alternative policy implementations (e.g., require all utilities to meet a specific planning reserve margin) or specific investment projects (e.g., invest in new controls at an existing power plant), to portfolios of projects (such as utility integrated resource planning [IRP]), up to very broad analyses spanning all known technologies (in the case of national-scale techno-economic or policy modeling). Thus, alternatives can be policies, projects, portfolios of projects, or technologies.

Technological alternatives may be relatively easy to identify; however, their valuation may be more difficult, particularly if an alternative technology provides more or different value streams in addition to the primary one for which it is originally considered. For instance, a valuation comparison of distributed energy resources (DER) versus central generation plants will require fundamentally different analytical valuation approaches, as DER often provide added value to the customer. A central generation plant, in comparison, may primarily provide value to the bulk power system.
Defining Strategies and Alternatives The TVA Integrated Resource Plan (IRP) provides a good example of identifying a range of alternatives (Step 2), and assessing impacts of each alternative (Step 9). In the TVA IRP alternative courses of action are called "strategies" that represent business decisions that TVA can control. These strategies are then evaluated in multiple scenarios, which represent uncertain futures that TVA cannot control. In consultation with stakeholders, TVA identifies five distinct strategies that account for differences in desired attributes of resource portfolios. One strategy is the "Reference Plan" against which all other strategies are compared. Each strategy is then evaluated across several different metrics, including cost, risk, environmental stewardship, flexibility, and local economics. The results for each strategy and each scenario are then presented in a common scorecard for easy comparison across alternatives. TVA 2015b

In most cases, budget and/or time constraints limit the number of alternatives that can be considered. The number should be sufficiently large that alternative viewpoints and perspective are taken into consideration. It is important to ensure that all reasonable alternatives are identified and vetted. Transparency in the valuation process will support this: while the formulation of the basic question/issue and its scope (Step 1) usually suggests alternatives, a key aspect of this valuation framework is to examine the issue from other stakeholders' perspectives to see if nontraditional alternatives should be evaluated. One of the motivators for developing the valuation framework is that new technology developments, market models, and grid configurations offer innovative alternatives that may not be considered if one only looks at, for example, different types of central generation plants as options for meeting load growth. A diverse set of stakeholders can be the sources of several alternatives, often injecting novel ideas into the more conventional solution set. Indeed, using stakeholder engagement (Step 3 ) to propose alternatives has been successful in promoting acceptance of valuation studies (see the sidebar for the TVA IRP).

All valuations should have a baseline alternative against which to compare other alternatives. Typically, this baseline alternative is a business as usual scenario in which the state of the world follows current practice. The baseline alternative will include a description of the expected current path of broad societal and financial parameters (e.g., inflation, growth rates, legal policies) that will be consistent through all alternatives, unless specifically altered for exploration of various alternatives' robustness. 
Feasibility considerations are important - there is no need to evaluate an alternative if it cannot be implemented without violating some hard constraints (e.g., a renewable energy resource capacity may have to meet a utility's generation adequacy requirements).

Sometimes the attribute whose value is to be characterized is very complex, multi-faceted, and imprecise - such as power system's resilience. In such a case, characterizing the level of resilience could lead to a comparison of options for strengthening certain aspects of resilience.

\section{Results/Documentation}

- Identification of the set of alternatives for consideration in the evaluation and boundaries.

- Specification of a business-as-usual case with which the value of other alternatives will be compared.

\section{Interaction with other steps}

This step also begins to specify the bases for comparison between alternatives. The specified bases for comparison (e.g., cost of electricity, emissions, reliability) will first be translated into the key high-level metrics (identified in Step 4). Weighting or prioritizing the metrics will be necessary to develop decision criteria to use in subsequent valuation steps (e.g., Steps 5 and 10). Stakeholder characterization and engagement (Step 3) will be a key determinant of this weighting. The nature of the alternatives to be considered will also inform the choice of methods and tools (Step 7), and the reasons for selecting the alternatives must be documented as part of Step 8 (assumptions and input data).

\section{Step 3: Plan and Initiate Stakeholder Engagement}

\section{Objectives}

Identify the stakeholders to be involved in the valuation study, define their roles, and develop a stakeholder engagement plan.

\section{Approach}

Stakeholder engagement is an integral part of the valuation process. Stakeholder engagement must be planned and initiated from the start, since it affects all the other steps. This step begins by identifying relevant stakeholders in addition to the organization initiating the valuation study (likely deemed the primary or principal stakeholder for the study). In this step, the entity conducting the study articulates the objectives, authorities and responsibilities of stakeholders in the valuation study as part of developing an engagement plan.

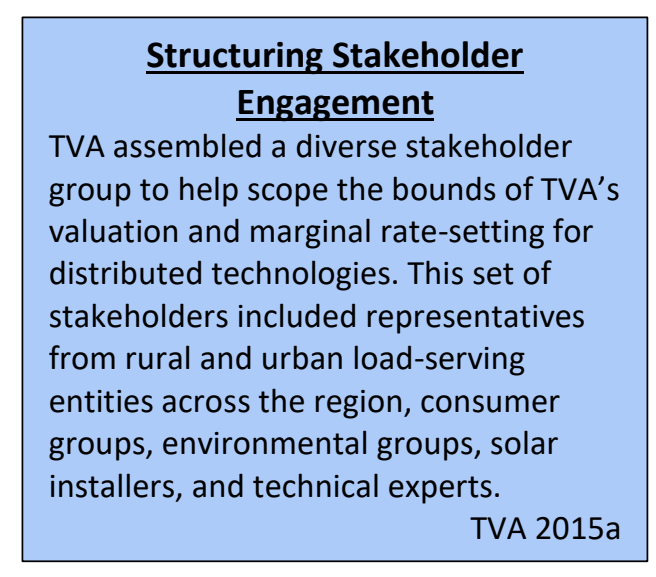

TVA $2015 a$

At the outset, the initiator of the study may postulate additional stakeholders' objectives and preferences based on the initiator's familiarity with each stakeholder's priorities and decision process, or on historical actions/decisions of a stakeholder. However, active follow-up and engagement with all relevant stakeholders is essential ${ }^{4}$ to help ensure that important analyses or metrics are not overlooked in the valuation and that any initial postulations about stakeholder perspectives are accurate. Meaningful engagement also may be necessary to ensure stakeholder buy-in to the option recommended by the valuation analysis. Stakeholders may be engaged through numerous methods, including direct polling or interviewing, advisory groups, holding workshops, and other, varied formal or informal interactions.

\footnotetext{
${ }^{4}$ Some level of cooperative engagement with stakeholders is important to obtain buy-in (and subsequent acceptance of results), but that may not always be possible, especially in existing forums likely to engage in valuation processes (PUCs, RTOs, FERC) that are often contentious and adversarial.
} 
In some existing PUC, Federal Energy Regulatory Commission (FERC), and regional transmission organization (RTO) forums where many valuation study opportunities might lie, existing prescribed processes (regulatory or legislative) may inhibit formal involvement by regulatory bodies in the early stages of the analysis. For example, the PUC may be required to rule on a utility's final submission and thus may not be allowed to be part of the analysis team that crafted it. In such cases, absent changes to regulatory policy or procedures, the analysis team must anticipate and allow for the objectives or viewpoints of the regulator in implementing the valuation framework.

\section{Results/Documentation}

- List of stakeholders to be involved in the valuation effort.

- Stakeholder engagement plan, specifying areas of expertise and roles of each stakeholder. It should describe how stakeholder input shall be solicited or, alternatively, if some stakeholders are strictly adversarial or prohibited from direct cooperation (by legal or regulatory procedures), how the valuation study will consider these stakeholders' objectives.

- Plan for interacting with stakeholders.

\section{Interaction with other steps}

Stakeholder engagement should be an integral part of Step 1 and Step 2 activities. But engaging with stakeholders, or anticipating stakeholder objectives or concerns, is part of every step. For this reason, anticipated stakeholder involvement is included in most valuation process steps.

\subsection{Phase B: Frame Valuation Criteria}

The next two steps frame the required information (i.e., metrics) necessary to characterize and evaluate alternatives, decision criteria for the study, and the approach to integrate or consolidate the metrics to portray the valuation of each alternative (steps 4 and 5). (Value is often a complex concept and may not be reducible to a single number or a quantitative tradeoff-relationship between metrics.) Specifying the valuation criteria requires selecting the highest-priority metrics as well as quantifying or otherwise specifying trade-offs among metrics.

\section{Step 4: Identify Key Metrics for Valuation}

\section{Objectives}

To identify all the performance characteristics, impacts, and other metrics that will inform valuations, and prioritize those metrics according to their influence on the choice of alternative. Specify how higher-level or composite metrics (e.g., reliability, environmental quality, job creation) can be expressed.

\section{$\underline{\text { Approach }}$}

Metrics used in valuation analyses are influenced by the nature of the question (e.g., if a PUC evaluates options by the resulting cost of electricity, then impacts on projected electricity prices are a metric) and by stakeholder input (e.g., if a utility requires that its generation plan include a loss of load probability [LOLP] of $<0.1$ day/year, then bulk power system reliability is a metric).

One resource that can be useful for identifying grid-related metrics is the Metrics Analysis reference document catalog developed by another GMLC project (Anderson et al. 2017). The document describes "existing metrics" and "metrics being developed." Since

Metric Selection Affects Solar Valuation

Two recent studies on the value of solar show how considering a different set of impacts can influence the total value reported. A Montana study gave a total value of around $4 \mathrm{c} / \mathrm{kWh}$ but a Maryland study showed 30 $40 \mathrm{c} / \mathrm{kWh}$. According to one reviewer, "the most significant valuation differences come down to methodology and what is counted as costs and benefits."

Trabish 2018 
new metrics and new combinations of metrics are continually being developed, that report suggests that the valuation framework must allow stakeholders to propose new or customized metrics to reflect stakeholder-specific objectives for grid performance. Therefore, for the valuation methodology, metrics will be classified as follows:

- Base or fundamental metrics are the direct outputs of models and effectively "state variables" of the grid. Base metrics would include LOLP, system average interruption duration index, electricity cost (\$/megawatt-hour [MWh]), line loading (amperes), peak load (megawatts), sulfur dioxide emissions, energy/load forecast (gigawatt-hours/year), and others.

- Custom or composite metrics combine metrics and other quantities to provide information addressing complex evaluation criteria or decision processes. As an example, Anderson et al. (2017) cites an affordability metric of percentage of household income that is spent on electricity. This composite metric combines information on electricity expenditures by customers (e.g., forecasted consumption by end users multiplied by average retail electricity rates) with information on state-level household incomes for different types of residential customers. ${ }^{5}$

Strong feedback received from the SAG was that metrics should not be limited to grid metrics. The decision regarding which alternative to choose often depends upon metrics that are not inherently related to the power system or grid, such as the overall economic health of the region. An example would be whether less costly or more reliable electricity would attract additional industries to the area, and to what extent. Such "non-electric" metrics as job creation can be addressed similarly to power system performance metrics. Basic metrics such as electricity cost and reliability could be among the inputs to a regional economic model that forecasts compound or "mega" metrics such as job creation or unemployment rate. For a valuation study, the differences in basic metrics for each alternative (e.g., electricity cost per kWh) could lead to different forecasts of economic indicators from a model of the region's economy.

The basic metrics and impacts needed for the valuation should be directly compared with the metrics and impacts that an analysis method or model provides as its output. Thus, it is necessary to match the analysis question's (Step 1) requirements for information with what candidate analysis models, tools, and methods (Step 7) can supply. Keeping this match in mind, Step 4 could use the following process to identify the basic metrics needed for the valuation:

A. Using stakeholder input/objectives (Step 3) and the scope of the question (Steps 1 and 2), identify all possible metrics and impacts to be reported/calculated as part of the valuation process. Use the metrics/impacts catalog (Anderson et al. 2017) as a guide for energy-related metrics. There may also be other non-power system metrics, such as economic indicators, that will influence the decision.

B. Determine (from all metrics in item A) which metrics or impacts are basic ones. Basic metrics or impacts are usually quantities that are direct outputs of a model.

C. If a metric identified in item A is not a basic quantity, then it is a custom or composite metric. Analysts should determine how that metric can be calculated from basic metrics and from other data. A list of basic metrics that compose the composite metrics will help to identify candidate methods and tools for the analysis. (Note that the sets of basic metrics that constitute different custom metrics will overlap.)

\footnotetext{
${ }^{5}$ The GMLC 1.1 Metrics Analysis Reference Document (Anderson et al. 2017) cites much ongoing research to develop, for example, forward-looking metrics that more effectively characterize resilience. The catalog of metrics developed by PNNL is valuable, but it is an evolving document, as the industry continues to develop new custom and composite metrics. Indeed, any new valuation exercise is likely to develop metrics customized to address the specific concerns and objectives of the involved stakeholders.
} 
D. Prioritize the metrics and impacts that will be calculated. Each metric used in the valuation study requires resources - personnel, time, data gathering, models, and so on. It may not be feasible to evaluate all the metrics. Therefore, this step must also prioritize which metrics will be evaluated, for example:

- Key metrics essential for the valuation;

- Significant metrics that should be calculated if possible; and

- Metrics "of interest" that will not significantly influence the choice of alternative.

The study organizers can decide which metrics to calculate, based on their own objectives and resource constraints.

E. The methods/formulae for calculating the compound metrics from the basic metrics, data, and other composite metrics become part of the Multi-Criteria Integration Approach (Step 5), the Selection of Methods and Tools (Step 7), the Impact Assessment (Step 9), and the Value Calculation (Step 10).

\section{Results/Documentation}

- Comprehensive list of metrics that could be used to categorize the attributes to be valued in the study;

- Prioritization of the metrics to identify those that can be calculated within the scope, schedule and budget of the valuation study;

- Approach to calculate/estimate composite metrics from base metrics

Interaction with other steps

Metrics are the "mortar" that holds together the building blocks of each step in the valuation framework. The nature of the evaluation question and basis for making a decision (Step 1) and qualities that differentiate alternatives (Step 2) are used to identify metrics. Prioritizing the metrics directly informs Step 5, Multi-Criteria Integration. Determining how each metric shall be calculated, estimated, and/or simulated informs the identification of uncertainties (Step 6), choice of methods and tools to be used in the study (Step 7), and requirements for data and assumptions to be made in order to perform the analysis (Step 8).

\section{Step 5: Develop Multi-Criteria Integration Approach}

\section{Objectives}

The objective of this step is to develop a method to assign comparative values to alternatives characterized by disparate metrics. Not all metrics and decision criteria can be reduced to or expressed in a common unit (e.g., dollar cost).

\section{Approach}

This step develops and explicitly shows the trade-offs among impact metrics. In a complex valuation study, elements (metrics and impacts) usually interact. For example, a technology or design option offering enhanced grid reliability may also result in higher operating costs and may also have adverse environmental impacts. The valuation framework allows for framing trade-offs, such as those among electricity costs, reliability, and environmental impacts, so as to help identify the "best" option. Much of the delineation of trade-offs of metrics comes from the articulation of stakeholders' objectives (Step 3). In mathematical programming/

\section{Multi-Criteria Impact} Presentation

The EIPC study of the Eastern Interconnection involved more than 80 various scenarios and a large set of metrics for each. Several methods were used to consolidate results into meaningful presentations, including cluster diagrams using double variables, heat map tables that vary the color of individual cells based on their value, and transmission flow maps between the regions with width and direction of lines varying. 
optimization terms, quantifying such trade-offs would define the objective function upon which the valuation analysis is based.

The output of this step is a clear presentation of the valuation-related integration process. Trade-offs do not always need to be described quantitatively. For example, in comparing two alternatives with different cost and reliability impacts, one cannot objectively equate the values of the two (e.g., $\mathrm{X}$ change in LOLP is worth $\mathrm{Y}$ increase in electricity costs $\$ / \mathrm{MWh}$ ). It is often sufficient to present clearly the results of the alternatives in terms of impact metrics (e.g., cost, reliability, emissions, land use) as a basis for discussion and debate among stakeholders.

The multi-criteria integration may include constraints as well as trade-offs among impact metrics: any option studied may first have to satisfy certain requirements before trade-offs are considered. For example, power systems must first meet certain reliability requirements from the North American Electric Reliability Corporation (NERC) (e.g., critical infrastructure protection, adequate level of reliability [ALR] requirements), as well as regional, state, and local reliability requirements. The alternatives of a utility's resource plan options will result in various electricity costs and reliability and environmental impacts. Before the valuation framework is used to frame a debate about trade-offs among these three metrics (to identify the best option), all options to be studied will probably be required to first satisfy conditions such as:

- NERC's ALR requirements;

- $\quad \mathrm{N}-1$ or better contingency response (e.g., NERC TPL-001);

- LOLP of $<0.1$ day/year;

- Acceptable ranges for system voltages and equipment loading;

- Environmental Protection Agency emissions requirements.

Constraints and requirements may also be characterized as hard or soft. For example, a normal rating loading constraint can be soft (meaning it is undesirable but acceptable), but an emergency rating loading constraint is hard.

\section{$\underline{\text { Results/Documentation }}$}

Methods to present and/or compare the values of alternatives as expressed by multiple metrics. If every attribute can be monetized, this task will be easier. However, because the methods and assumptions to monetize a metric may be controversial, the monetization methods must be documented. (e.g., what is the cost to the consumer of an electrical outage?)

Where multiple criteria cannot be reduced to a single common unit, the trade-offs can be shown (e.g., cost of electricity versus level of $\mathrm{SO}_{2}$ emissions). For some criteria, especially environmentally based or reliability-based criteria, there may be requirements that must be met (e.g., maximum allowed emissions). (See the sidebar on the EIPC's Eastern Interconnection study for examples of how to document multiple criteria to facilitate understanding.)

\section{Interaction with other steps}

The manner in which multiple criteria are viewed in the valuation process is influenced by the stakeholders (Step 3) and the metric prioritization (Step 4). In turn, the articulation of how multiple criteria are viewed for valuation analyses helps determine how integrated values are calculated for each alternative (Step 10) and how the results are presented and interpreted to support the decision-making process (Step 11). 


\subsection{Phase C: Design Analysis}

The three steps in this phase construct the study, including the methods, tools, assumptions, and input data to be used (Steps 7 and 8). This effort includes determining the methods to consider uncertainty in the analysis and consolidated impacts from the different alternatives (Step 6).

\section{Step 6: Determine Approach to Handle Uncertainty}

\section{Objectives}

To identify the unknowns and uncertainties inherent in forecasting, modeling, and valuation. To determine how to deal with and document these uncertainties (or estimates) in the analysis.

\section{Approach}

There are varied kinds of uncertainties that come into play during the course of valuation analyses, and that are associated with grid-related decision making that may be based partially or entirely on the results of valuation analyses. Illustrative categories of uncertainties include the following:

- Data-related uncertainties

- No data, or gaps in time-series data

○ Incomplete or inaccurate data

- Forecasting future year conditions

- Price/cost-related: Future year forecasts of equipment/technology prices, fuel costs, labor costs, outage costs

- Capability-related: Uncertainties in technology development predictions (especially accounting for the results of current research and development) translate into uncertainty about equipment reliability/availability, performance characteristics (e.g., efficiencies, losses), operations and maintenance needs, other costs and prices

- Load or growth forecasts

- Event-related uncertainties: uncertainties regarding an event's occurring can include

- A forced outage of a generator, power line, transformer or other grid component

- Demand for power (i.e., load forecast, including time and spatial components)

- Costs-e.g., price of natural gas

- Occurrence or probability (e.g., frequency, magnitude) of an extreme event, such as a terrorist attack, solar flare/geo-magnetic disturbance, hurricane, flood, or earthquake

$\circ$ Weather - temperature, rainfall, wind, solar incidence

- Power system-related uncertainties: uncertainty about the state of the power system (e.g., after an event, what components are out of service)

- Analysis method-related uncertainties: simulation and forecast analysis methods, tools and models can only estimate outcomes (impacts and metrics)

These kinds of uncertainties can be addressed through multiple methods (used singly or in combination):

- Use of expected value or most likely value

- Use of a range of values (e.g., high, medium, low forecasts)

- Stochastic techniques (probabilistic modeling), such as

- Monte Carlo analysis

○ Probability density functions (e.g., Booth-Baleriaux method for production costing)

- Probabilistic risk assessment 
- Sensitivity studies

- Contingency planning studies (e.g., loss of the first, second, third, etc. -largest generators or linescontingency modeling is used to meet NERC ALR requirements; force 5 hurricane; high-altitude electromagnetic pulse event of $\mathrm{X}$ magnitude)

- Definition of scenarios incorporating many assumptions and input values in a consistent manner (such as tabletop exercises).

Uncertainties can be treated as risks for the valuation evaluation processes. Risk identification and risk management/mitigation is a well-researched field. The Department of Defense (DoD) Risk Management Guide for DoD Acquisition, Sixth Edition (DoD 2006), provides a disciplined environment for proactive decision making to identify and mitigate risks.

The DoD approach results in a clear enumeration of identified uncertainties and a uniform format to describe how each uncertainty was assessed and addressed. This attention to uncertainty is an important differentiator from how many valuation studies are conducted. Often, the decision of how to deal with an uncertainty is made implicitly and never documented. Thus, a model may be chosen (e.g., for dealing with probabilistic uncertainty) or a mid-range forecast may be used (for dealing with predictive uncertainty about the future) as the customary way a consultant/analyst approaches that particular modeling exercise. However, the choice — and the reasons for it - may not be appropriate or accurate, and such a modeling flaw may not be detected because the choice of model/method was not documented.

This step usually requires that knowledgeable domain analysts familiar with the techniques for dealing with uncertainties, and their strengths and weaknesses, be engaged for this portion of the analysis. The value of this approach is that it clearly and transparently identifies uncertainties in the valuation process and explains how and why they will be considered.

\section{$\underline{\text { Results/Documentation }}$}

Comprehensive documentation of the uncertainties inherent in the valuation methodology and the ways they are addressed.

\section{Interaction with other steps}

If specific modeling methods are chosen to deal with uncertainty, these methods can be compared with characteristics of potential tools and models to identify which models are compatible with the selected risk/uncertainty management approach (Step 7). The available budget and schedule (i.e., the study's resource constraints) as set forth in the analysis plan (Step 1/Phase A) will help determine the extent to which various uncertainties can be addressed.

\section{Step 7: Select Assessment Methods and Tools}

\section{Objectives}

To select appropriate analysis methods, tools, and models consistent with the information needs previously identified and feasible within the budget and schedule set for the study.

\section{Approach}

This step includes the selection of methods, models, and tools to calculate the impact metrics upon which valuation-related findings will be based. Models will be described or characterized using (but not limited to) the following information:

- Type of model or tool (e.g., load flow [static/dynamic], transient stability, reliability, contingency analysis, load profile, price elasticity, load forecast, revenue requirements, generation expansion, production cost, unit commitment) 
- Subsystem/sector (e.g., generation, transmission, substation, distribution, microgrid/feeder, customer, load[s], combinations)

- Geographic area or territory: World, North America, United States, interconnection, area served by a regional transmission or independent system operator, state-level area, utility, local area, substation, feeder(s), microgrid, campus, customer premises

- Time frame and resolution (micro-seconds to years), considering whether the focal grid-related valuation is for planning, for operations, or for developing operating procedures (planning for operations)

- Is the model for calculation (e.g., load flow, reliability) or optimization (e.g., production cost)

- Constraints in model calculation (e.g., equipment loading limits, reliability/LOLP required)

- Variables used for optimization (e.g., minimize fuel and operating costs)

- Model outputs (to be compared with basic metrics identified in Step 4): examples are loading, economics (capital and operating and outage), reliability (various indices and metrics), rates/tariffs, environmental effects

- Required inputs (e.g., are the data available, accessible, affordable?)

- Methods to handle uncertainty (e.g., stochastic techniques)

- Model ownership and licensing requirements.

Recognizing that valuation is a process, it is important to exercise consistency checks as part of that process to ensure that the analysis methods and tools do in fact accurately calculate the metrics and impacts upon which the decision (regarding which alternative offers the best value) will be based. The result of this step is a comprehensive and quantitative listing of the information requirements needed to perform the valuation analysis. The scope of the study (e.g., distribution system vs. bulk power system; utility service area vs. a city vs. a substation and its feeders) and the information required to choose among alternatives (metrics) inform what analysis methods and tools may be suitable for the valuation.

\section{Results/Documentation}

Documentation of a detailed calculation approach and data flows to provide the necessary metrics for a decision. The models and methods will have been chosen to ensure that the tools' purposes, capabilities, and outputs match the scope and requirements of the valuation question. (See the sidebar on MISO's multi-value transmission project for an example of good practice.)

\section{Interaction with other steps}

Models suggested for the valuation process will be those with the capability to calculate the basic metrics that have been designated as key. The characteristics of candidate models will be compared with the study requirements (as defined by Steps 1, $2,4,5,6)$. The methods to derive composite metrics from basic metrics (Step 4) and to integrate multiple criteria into the evaluation and decision processes (Step 5) provide the equations,

\section{Documenting Selection of} Assessment Methods

Midcontinent Independent System Operator (MISO) evaluated the impacts of the Multi-Value Transmission Project Portfolio, a series of large transmission investments whose costs are spread across the North and Central regions of MISO's footprint. This study provides a clear example of how to document the choice of assessment methods and tools (Step 7) for complex, multi-faceted studies. data flows, and other methods to derive the required information from the basic metrics (i.e., model outputs). 


\section{Step 8: Develop Assumptions and Input Data}

\section{Objectives}

To identify and document all sources of data and simplifications or assumptions made during the analysis.

Approach

This step identifies the sources of data and documents any assumptions, simplifications or bounds on the models or tools used. Transparency about these selections is often crucial to the acceptance of the valuation; stakeholders will want to be able to examine the basis behind the assumptions and input data and potentially proffer alternate values. (However, care must be taken to protect certain Critical Energy Infrastructure Information or confidential data sources.) The choice of assumptions about the state of the region and the power system and its customers will have substantial impacts on the quantitative results of the modeled alternatives. Even choosing initial values can be difficult. Power system models are complex, often requiring voluminous and detailed input data. The input data must be consistent across the different models employed in the valuation process. Care must also be taken that the outputs of a model have the proper units, resolution, and aggregation when they are used as inputs to another model.

\section{Results/Documentation}

A comprehensive list of data sources and assumptions made.

\section{Interaction with other steps}

The assumptions and key input data are influenced by the model and tool selection (Step 7) the metrics (Step 4), the means of comparing or presenting values based on multiple criteria (Step 5), and the handling of uncertainties (Step 6). The analyst team will decide which data source(s) to use. A literature search to find similar valuation studies (Step 1) may help identify data sources. In the course of executing this task, data may be unavailable or unreliable. In that case, an alternative approach may be needed, and the project team may have to go back to Step 7 to select a different model or analysis method; the new model must be checked against the study scope and information requirements to ensure it meets the information needs of the study.

\subsection{Phase D: Determine and Present Results}

The three steps of the last phase are the calculation of key metrics; interpretation and presentation of the resulting values; and reporting of the comparison among various alternatives to guide decision making.

\section{Step 9: Assess Impacts for Each Alternative}

\section{Objectives}

To exercise the analysis methodology and calculate the impacts/metrics of each alternative.

\section{Approach}

Conceptually, this step is straightforward: simply perform the analyses using the methods, tools, models and input data previously selected. With the valuation study modeling framework and assumptions assembled, the chain of models and analyses are executed to produce quantified impacts of different metrics across the range of alternatives defined in Step 2, including the baseline or business-as-usual case. The models, simulations, and cases must also reflect the methods chosen to deal with uncertainties (Step 6), possibly including additional scenario analyses, sensitivity analyses, and/or Monte Carlo simulations. The impacts should be quantified over the full time-horizon for which the actions and alternatives are expected to produce differences with the baseline case. 


\section{Results/Documentation}

The expected impacts and characterization of each alternative, as calculated using the tools, data and methods of the previous steps.

Interaction with other steps

The metrics and impacts will be used to calculate the value of each alternative (Step 10) using the multicriteria integration approach developed in Step 5.

\section{Step 10: Calculate Integrated Values for Each Alternative}

\section{Objectives}

To present the metrics and impacts for each alternative that are used to assess its value.

\section{$\underline{\text { Approach }}$}

This step calculates integrated values for each alternative based on quantification of alternatives using the multi-criteria approach defined in Step 5. If tools such as surveys and interviews are used, their more qualitative results may need to be integrated with the quantitative modeling outputs before values for each alternative can be determined.

Depending on the method of integration and communication, this task can be as simple as totaling financial estimates, or as complicated as soliciting priorities, ranks, and weights from a variety of stakeholders. Variations on the integration criteria may be applied to better understand the perspective of various stakeholders or simply the robustness of the integrated value. Results after applying uncertainty factors can also better inform the fully integrated results for each alternative.

\section{Results/Documentation}

The combined elements of expected impacts of each alternative necessary to express its relative value.

Interaction with other steps

The valuations of each alternative will be compared in the final step. 


\section{Step 11: Compare Values, Document Analysis, and Report Findings}

\section{Objectives}

To present the relative valuations of each alternative in a format that facilitates objective comparison by decision makers and other stakeholders. To prepare a final report and complete comprehensive documentation of the valuation study.

\section{Approach}

This step documents the findings, including the opportunity to publish a matrix of metrics, if appropriate, rather than try to combine all metrics into a single valuation number/index/metric. Step 1 (Stakeholder Engagement) and Step 5 (Multi-Criteria Integration Approach) inform the format and content of the presentation of valuation findings. Steps 8 (Assumptions and Input Data), 9 (Calculate Impacts), and 10 (Calculate Integrated Values) determine the numeric values.

\section{Results/Documentation}

The final report and documentation of all methods, data and assumptions upon which the evaluation was based. (See the sidebar on DOE's WindVision study and its communication of results.)

\section{Interaction with other steps}

Each step has documentation requirements that, taken together, should in theory fulfill the needs of this final step. In fact, it is expected that the documentation produced previously in the process will be reviewed for completeness and consistency.

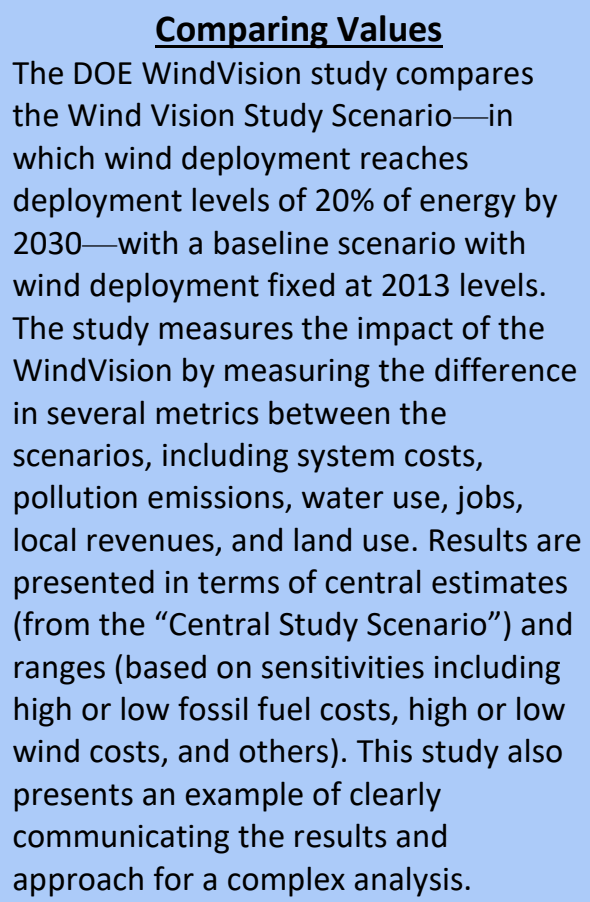

DOE 2015 


\section{Review of Other Industries' Process Standards}

\subsection{Introduction}

With a long-term vision of developing a framework that could become codified as generally accepted valuation principles, several key questions must be answered:

1. Do standards exist, albeit in different industries, that successfully codify and standardize processes similar to the kind of valuation process proposed in GMLC 1.2.4?

2. If yes, what are some of the lessons learned that could be useful for directing future work towards developing commonly accepted methods for valuation?

The team reviewed standards, protocols, and guidelines for processes in other industries that had similarities to the valuation process as defined in this project. The objectives were 1) to glean insights into the applicability of standardizing or otherwise making more uniform a complex process with many actors, and 2) to assess whether some of those existing protocols and standards could serve, to some degree, as models and lessons learned for valuation of grid modernization alternatives. A companion report ${ }^{6}$ provides more details on the standards review.

The review undertook a brief analysis of eight sets of principles, checklists or standards that are widely used in business and industry in the United States to set guidelines or establish thresholds for accuracy, transparency, consistency, repeatability, quality, and/or extensibility, including:

- $\quad$ The GAAP;

- International Organization for Standardization (ISO) 9000 series;

- ISO-14040 series;

- Aviation checklists;

- Medical checklists;

- American Society of Heating, Refrigerating and Air-Conditioning Engineers, Inc. (ASHRAE) Standard 202-2013;

- NERC bulk electric system reliability standards; and

- $\quad$ Rhode Island (RI) benefit-cost analysis framework. (Raab et al. 2017)

\subsection{Commonalities}

The standards and guidelines reviewed have several commonalities with the proposed valuation framework.

\section{Consistent Framework}

The purpose of most of the standards is to outline a framework requiring use of consistent methods, laying out minimum requirements and, in some cases, pointing to the need for data from reputable sources. The intent is to reduce if not eliminate the opportunity for organizations to produce results that further a narrow, special interest and/or to ensure that the organizations do not overlook key steps in the

\footnotetext{
${ }^{6}$ Cooke, Alan, et. al., Evaluation of Process-Based Standards, Pacific Northwest National Laboratory, Report XXXX, April 2019.
} 
process. For several standards, the intent is to identify the minimum set of required steps needed for success.

GAAP is literally concerned with ensuring that accurate financial reports are prepared for the use of stakeholders (e.g., investors) who require accurate and unbiased financial information that can be compared with the financial information of other entities.

ISO-9000 focuses on data-driven decision making and quality management practices, including consistent management tools and practices, timely and accurate records management, and a planning process that takes into account stakeholders (e.g., suppliers, contractors, customers, employees) and the full range of impacts.

ISO-14040 series, in particular ISO-14044, lays out a consistent framework for the analysis of environmental impacts. ISO-14044 addresses a real need that had been recognized historically when organizations made conflicting claims backed up by their "home-grown" analyses.

Checklists, aviation and medical, exist to lay out the minimum required steps to ensure that no critical component is overlooked.

NERC standards and ASHRAE 202-2013 achieve their success by ensuring that important and specific details are not overlooked and that all identified steps are taken. NERC standards set minimum thresholds for electric system reliability. ASHRAE 202-2013 describes the activities that are characteristic of best practices for achieving designed operational performance of buildings' structure and HVAC systems; it does not set quantitative requirements.

The RI framework includes a CBA step that lists benefits and costs to be analyzed as well as a policy framework identifying the specific areas that must be addressed at some level.

\section{Industry Stakeholder-Developed}

Issues faced by industry participants can be successfully addressed by standards developed by the industry.

NERC's reliability standards are developed by drafting teams composed of industry participants. Approval by a ballot body drawn from industry participants is a required step. The initiating step-a standard authorization request — can be submitted by any industry stakeholder.

ASHRAE 202-2013 is developed and maintained by a standards committee composed of the ASHRAE membership, and the process of updating the standard is generally started when a stakeholder submits a change proposal. All ASHRAE standards undergo extensive open public review.

ISO standards are also developed by committees composed of member representatives who are experts in the committee's subject area. Accordingly, ISO-9000 is developed by member representatives with quality management expertise. Standards must be approved by a membership ballot.

The RI framework was developed through a stakeholder process, and the working group came up with a unanimous, consensus proposal. (The utility regulator set it up to be a stakeholder process.)

GAAP standards or rules are developed by the Financial Accounting Standards Board (FASB); but the process includes significant amounts of stakeholder input, and one of the mechanisms for initiating a standard development/update process is a stakeholder request or recommendation. 


\subsection{Lessons Learned}

Following are some of the lessons that can be drawn from the guidelines and standards reviewed.

Brief and highly focused is better. This lesson comes from the checklists. Busy schedules, interruptions, and short attention spans are common in modern business. The best approach might be a short document that hits the essential items succinctly.

Organizational culture is a key. The ISO standards, GAAP, checklists, and NERC standards all recognize that culture is a potential issue; and they all have focus on leadership responsibility and/or how the team interacts. For example, the medical checklists have steps explicitly calling for team meetings to discuss what is being done and an approach to ensure that everyone is on the same page, so that staff do not, for example, simply arrive at an operating room, perform an operation, and leave. ${ }^{7}$

A focus on stakeholders (or "seams") is a key. The ISO and ASHRAE standards have elements that cause the organization to identify key stakeholders in the process and to either explicitly work with them, provide data to or collect data from the stakeholders, or at least reflect their perspectives in the process. ${ }^{8}$ The medical checklist team meetings are almost explicitly a "seams issue," requiring that team members coming from different medical professions talk and plan together.

ISO, ASHRAE, and NERC provide models for standard development. All are standards developed with significant opportunities for stakeholder input.

\subsection{Successful Outcomes}

The reviewed standards all demonstrated successes.

GAAP has tackled some very sticky issues, such as the true market value of an investment versus the book value, and the treatment of off-balance-sheet items such as special-purpose entities. Both issues had constituencies that quite literally fought back - including asking Congress for legislative relief. FASB can succeed at addressing such issues in part because the governing board is independent from the various stakeholder groups.

ISO-9000 successfully puts the focus on customer needs and quality management systems. Currently, over a million entities have been certified under ISO-9001 worldwide, 39,000 of which are in North America.

ISO-14044 is a credibility-building analysis insofar as it lays out a process for evaluating environmental impacts which, when paired with what is called Type III environmental declarations, can be used to credibly establish that the entity has subjected its product to an environmental assessment.

Aviation checklists are a key factor in aviation safety. The speed at which change propagates through aviation checklists is impressive. A book, The Checklist Manifesto by Atul Gawande, recounts the story of a crash and the lessons learned. It took a matter of months to complete the crash investigation, but about 10 months after the first crash, another was averted because the crew had a checklist.

\footnotetext{
${ }^{7}$ While it might be hard to believe, apparently it is not uncommon for this to happen.

${ }^{8}$ NERC standards also contain requirements for seams issues and stakeholder involvement, though individual standards' content was not explicitly discussed in this report. For example, TPL-001-4, Transmission System Planning Performance Requirements, includes requirements for working with neighboring systems' transmission planners and a stakeholder involvement process requirement related to "non-consequential load loss."
} 
Medical checklists have been demonstrated to be capable of helping hospitals all but completely eliminate errors caused by skipping or forgetting simple steps, such as washing hands or washing the patient's skin at the point of incision. Both medical and aviation checklists are potential culture changers insofar as they empower all participants to serve as backstops to other participants; and in both cases, they empower staff (e.g., a first officer or a nurse) to question the lead (pilot or doctor) to ensure that all important issues have been addressed.

ASHRAE's commissioning Standard 202 has been demonstrated to help the building industry deliver buildings that meet the advertised criteria and needs of the building occupants. It also responds to the needs of the utility industry and others who operate energy efficiency programs. Before commissioning became somewhat common, there were commonly failures in operations or performance because subsystems or processes had not been properly interfaced or because quality checks had not been performed. The ASHRAE model for setting and updating standards is a model that should be considered for the valuation framework. While the ultimate decision making rests with the committee that controls the standard, there are several opportunities for public comment as the standard is proposed, scoped, written, and updated. ASHRAE addresses all negative comments to the extent possible. The model is structured to get public comment from all stakeholders without creating an unwieldy structure.

NERC reliability standards are successful stakeholder-driven standards that have been shown to yield successes relative to historical results, such as decreasing transmission outage trends for the past 5 years and decreasing rates of protection system mis-operation. The standards themselves are developed by stakeholders, and stakeholder approval via a ballot body is a required step.

The RI framework is too new to identify a specific success resulting from the standard. However, the RI regulator that set up the process in its order accepting the stakeholder report stated that it was pleased that the process was able to achieve unanimous consensus on all but one issue.

\subsection{Considerations for Increasing Consistency of Grid Valuation Processes}

The standards review provided valuable insights into the potential for the valuation guidelines to lend themselves to being codified in some industry-adopted language or principles to improve the credibility, transparency, and overall acceptance and use of the valuation effort. The review strongly indicated that other very process-oriented activities do lend themselves to be formulated into standards language, and there is evidence that such standards or consistency in processes have improved the overall confidence in the quality of products.

It therefore appears feasible that the valuation guidelines would be codifiable by some industry body. The questions then are whether there is sufficient interest by the industry to continue such an effort, and how this effort would be structured and governed. The objective of the next phase of the GMLC Grid Valuation Framework Development project is to answer these questions and, if suitable, further advance the framework through assisted application by industry and discussions with potential requirementsdefining or standard-setting bodies. 


\section{Conclusions and Next Steps}

This project developed an 11-step valuation process in collaboration with an SAG. Several in-person meetings and webinars with SAG members confirmed the need for consistency in the process of determining the value of potential grid modernization actions (i.e., designing and executing a valuation study).

During the process development, the team tested the process on two test situations. These provided important insights into how decision makers approached valuation and what information was needed to choose among grid modernization alternatives.

We explored the applicability of establishing some form of standard for the process of grid valuation by reviewing the governance of complex processes in other disciplines. This review strongly indicates that industry groups in the buildings sector (heating, ventilation, and air conditioning), management, environmental, accounting, medical, and aviation fields have successfully established standards or standard-like guidelines that improve the quality of performance or services. The benefits from standards developed for other process-based disciplines suggest that - with sufficient interest by stakeholders of the electricity sector-similar efforts may be feasible and beneficial for evaluating grid modernization proposals.

Consistent with the vision for this project, the suggested next step would be applying this framework of an 11-step valuation process to ongoing valuation studies supporting grid modernization decisions. That step would refine and elaborate the guidelines and gauge the interest of the stakeholder community in continuing toward developing standards and best practice requirements to be applied to valuing grid modernization actions. 


\section{References}

Anderson, D., A. Eberle, T. Edmunds, J. Eto, S. Folga, S. Hadley, G. Heath, et al. 2017. Grid Modernization: Metrics Analysis (GMLC 1.1) Reference Document, Version 2.1, PNNL-26541, Pacific Northwest National Laboratory, Richland, WA, May. Available at https://gridmod.labworks.org/sites/ default/files/resources/GMLC1\%201_Reference_Manual_2\%201_final_2017_06_01_v4_wPNNLNo_1.p df. Accessed January 2019.

Boardman, Anthony, David Greenberg, Aidan Vining, David Weimer, Cost-Benefit Analysis, 3rd Edition, 2006, Pearson. https://www.pearson.com/us/higher-education/product/Boardman-Cost-Benefit-AnalysisConcepts-and-Practice-3rd-Edition/9780131435834.html. Accessed January 2019.

Cooke, Alan et al. 2019, Evaluation of Process-Based Standards, Pacific Northwest National Laboratory, Report XXXX, April.

DOE (US Department of Energy) 2015. Wind Vision: A New Era for Wind Power in the United States, US Department of Energy, Washington DC, March. Available at http://www.energy.gov/sites/prod/files/ WindVision Report final.pdf. Accessed January 2019.

EIPC (Eastern Interconnection Planning Collaborative) 2011. Phase 1 Report: Formation of Stakeholder Process, Regional Plan Integration and Macroeconomic Analysis, Eastern Interconnection Planning Collaborative, December. Available at http://nebula.wsimg.com/44f0897683f915dac648f22ac80624b5? AccessKeyId=E28DFA42F06A3AC21303\&disposition=0\&alloworigin=1. Accessed January 2019.

Markel, L, S. W. Hadley, P. W. O’Connor, A. K. Wolfe, V. Koritarov, M. Kintner-Meyer, M. Ruth, G. Porro, A. Cooke, A. D. Mills, V. N. Vargas, C. A. Goldman, P. Gagnon, A. Somani, R. F. Jeffers 2019. A Valuation Framework for Informing Grid Modernization Decisions, Oak Ridge National Laboratory. Draft, April.

Midcontinent ISO 2017. MTEP17 MVP Triennial Review, Midcontinent Independent System Operator, Carmel, Indiana, September. Available at https://cdn.misoenergy.org/MTEP17\%20MVP\%20Triennial\% 20Review\%20Report117065.pdf. Accessed January 2019.

Raab Associates, Paul Centolella \& Associates, Tabors Caramanis Rudkevich 2017, Docket 4600: Stakeholder Working Group Process - Report to the Rhode Island Public Utilities Commission, Raab Associates, Ltd. Boston, MA. Available at: http://www.ripuc.org/eventsactions/docket/4600WGReport 4-5-17.pdf. Accessed February 2019.

TVA (Tennessee Valley Authority) 2015a. Distributed Generation-Integrated Value (DG-IV): A Methodology to Value DG on the Grid, Tennessee Valley Authority, Knoxville, TN, October. Available at http://www.tva.gov/dgiv. Accessed January 2019.

TVA (Tennessee Valley Authority) 2015b. Integrated Resource Plan-2015 Final Report. Tennessee Valley Authority, Knoxville, TN. Available at https://www.tva.com/Environment/EnvironmentalStewardship/Integrated-Resource-Plan/2015-Integrated-Resource-Plan. Accessed January 2019. 


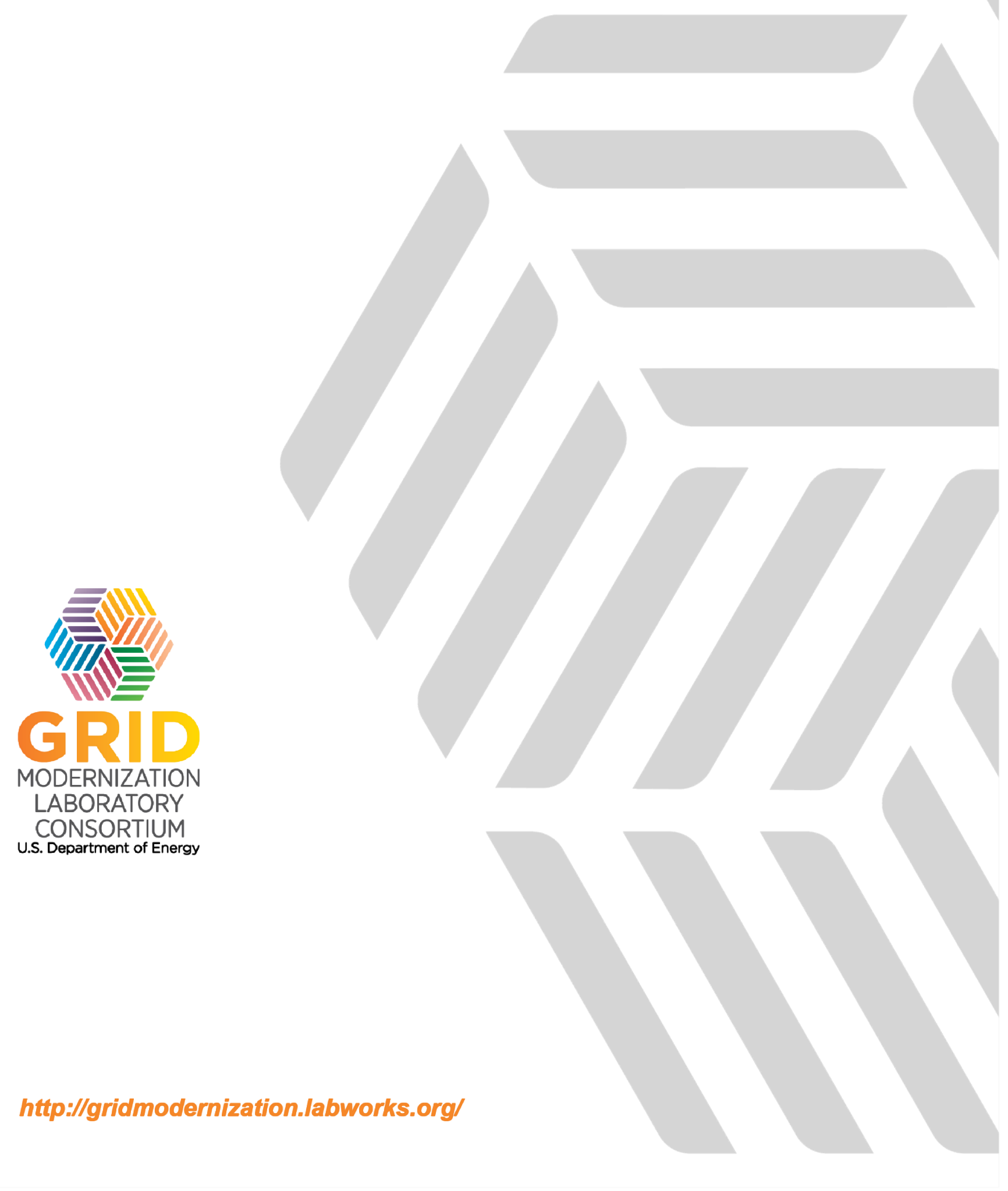

